\title{
Cooperação internacional e bioprospecção no Brasil e no Peru
}

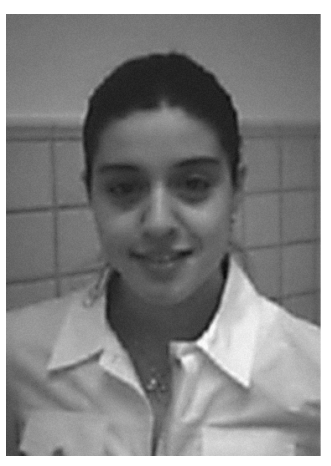

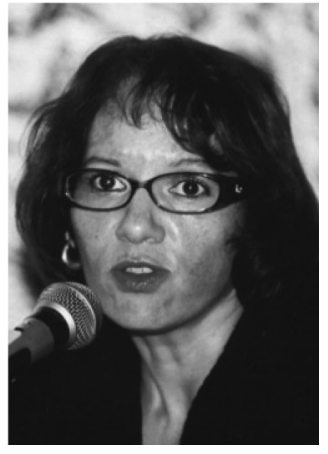

\section{Resumo}

Este trabalho refere-se ao projeto "Natureza e Impacto de Parcerias Norte-Sul, Público-Privado em Pesquisa Aplicada à Bioprospecção", que tem por objetivo investigar a natureza e identificar a contribuição da cooperação norte-sul em bioprospecção como mecanismo de promoção das capacidades científicas e tecnológicas dos países do sul. A metodologia baseia-se em estudos de caso realizados no Brasil, Peru, Colômbia e Suriname. Apresentam-se resultados preliminares da análise da prática bioprospectiva em dois países, Brasil e Peru, com base na análise de três arranjos de bioprospecção ocorridos nestes países, entre 1993 e 2001.

\section{Palavras-chave}

Cooperação Norte-Sul, desenvolvimento, bioprospecção, Brasil, Peru

Esta comunicação refere-se ao projeto "Natureza e Impacto de Parcerias Norte-Sul, Público-Privado em Pesquisa Aplicada à Bioprospecção", desenvolvido no Departamento de Política Científica e Tecnológica da Universidade Estadual de Campinas (DPCT-UNICAMP), sob a coordenação das pesquisadoras Léa Velho e Maria Conceição da Costa, com o apoio do International Development Research Centre (IDRC). O projeto tem por objetivo investigar a natureza e identificar a contribuição da cooperação norte-sul em bioprospecção como mecanismo de promoção das capacidades científicas e tecnológicas dos países do sul. A metodologia baseia-se em estudos de caso realizados no Brasil, Peru, Colômbia e Suriname. Aqui, são apresentados resultados preliminares da análise da prática bioprospectiva em dois países, Brasil e Peru.
A preocupação dos países avançados no sentido de colaborar com os países do Terceiro Mundo para que atinjam desenvolvimento econômico é antiga e faz parte do discurso político de um número considerável de nações. Nesta linha, a partir da década de 50 do século XX, vários países criaram suas agências de cooperação para o desenvolvimento. As agências pautaram-se por um tipo de atuação, voltado, em grande medida, para a doação sem fins lucrativos centradas em atividades científicas, diante do crescimento da importância e das necessidades da ciência e tecnologia, num momento de crescimento e consolidação das nações capitalistas. Até a década de 50, estas ações estiveram direcionadas para áreas mais carentes de pesquisa, como, por exemplo, saúde, sanitarismo, agricultura e educação. 
À luz da cooperação internacional, a bioprospecção tem se revelado uma área fértil para investigação. É sabido que os centros mais dinâmicos da atividade biotecnológica encontram-se, fundamentalmente, no hemisfério norte, nas sociedades de capitalismo avançado. Por outro lado, as principais reservas de biodiversidade estão, em larga medida, concentradas no hemisfério sul, em sociedades situadas nos estágios menos avançados do desenvolvimento capitalista. Deste modo, a atividade de bioprospecção possibilita construir um quadro das diferentes maneiras nas quais os benefícios para os participantes podem derivar das parcerias, além de identificar condições políticas e socioeconômicas em que as parcerias podem contribuir para o desenvolvimento sustentável.

A bioprospecção envolve a coleta de material biológico e o acesso a recursos genéticos em busca de novos compostos cujos princípios ativos possam ser aproveitados para a produção de produtos ou processos. As matérias-primas da prática bioprospectiva consistem nos conhecimentos prévios a respeito da natureza e nos recursos biológicos disponíveis em determinada região. A bioprospecção apóia-se não apenas nos conhecimentos desenvolvidos no âmbito das instituições e laboratórios de pesquisa, mas, igualmente, num legado de tradições e saberes populares, nem sempre codificados, passados de geração para geração.

O processo de regulação das atividades de bioprospecção é relativamente recente. A Convenção sobre Diversidade Biológica $(\mathrm{CDB})$, aprovada no Rio de Janeiro em 1992, é o tratado internacional que estabelece os parâmetros para a conservação da biodiversidade e para a utilização sustentável de seus componentes. Desde então, estes componentes são considerados objeto da soberania dos Estados Nacionais e não mais um patrimônio comum da humanidade. $\mathrm{O}$ acesso a estes recursos está condicionado ao consentimento prévio de seus detentores e à negociação dos termos de repartição dos benefícios entre as partes.

A prática bioprospectiva é, possivelmente, um dos campos do desenvolvimento científico-tecnológico contemporâneo que mais coloca em evidência uma miríade de tantos atores: indústria, comunidades autóctones, agricultores, consumidores, ambientalistas, instituições de pesquisa, organizações não-governamentais, governos locais e seus representantes e dirigentes de organismos internacionais. Isto confere à bioprospecção o caráter de uma prática coletiva condicionada por outras práticas sociais, que inclui cientistas e não cientistas (LATOUR, 2000) e que instiga questões relativas: à lógica e à ética da investigação científica (SHIVA, 2004; SANTILLI, 2004); à definição dos legítimos representantes dos atores envolvidos (GREENE, 2004); à ecopolítica das relações internacionais (LEPRESTRE, 2000; TOBIN, 2005); ao significado de soberania e aos conceitos de Estado e nação (BRUSH, 1999) - ao contrapor necessidades e expressões de povos indígenas, seus territórios e os Estados que os delimitam (COOMBE, 2005); às fronteiras entre natureza e cultura (LATOUR, 2004); e aos limites da regulação internacional quanto aos direitos de propriedade sobre os conhecimentos tradicionais (CARNEIRO DA CUNHA, 1999; DUTFIELD, 2004).

No Brasil, a mais importante empresa de bioprospecção, Extracta Moléculas Naturais S.A., foi criada em 1998 dentro da Fundação Bio Rio, incubadora de biotecnologia do Rio de Janeiro. Desde o inicio de suas atividades, a empresa optou por parcerias com sócios estrangeiros. Inicialmente, tinham um sócio inglês, Xenova Group PLC, uma pequena indústria farmacêutica inglesa, contato estabelecido por conta de uma pesquisadora da Universidade Federal do Rio de Janeiro (UFRJ) que havia realizado seu doutorado na Inglaterra alguns anos antes. No mesmo ano estabeleceu-se um contacto informal com o então presidente da Glaxo-Wellcome Latino-América que propôs uma espécie de contrato de "terceirização tecnológica”. Este contrato previa a detecção de novas moléculas para medicamentos, sendo que a patente, na época, seria da Extracta.

Em julho de 1999, a Extracta e a Glaxo-Wellcome firmaram um contrato para colaboração na triagem de materiais derivados de fontes naturais visando a procura de moléculas singulares. A existência deste contrato veio a público quando foi citado pelo presidente da Glaxo-Wellcome, em depoimento prestado à Comissão Parlementar de Inquérito (CPI) dos Medicamentos, em abril de 2000, caracterizando-o como o primeiro projeto de pesquisa firmado entre uma empresa multinacional e uma companhia local de biotecnologia, após a aprovação da Lei de Propriedade Intelectual. Na época, foi um dos maiores acordos de pesquisa na área de produtos naturais, com investimento de US\$3 milhões, aplicados durante três anos. Na ocasião, a Extracta empregava 60 pesquisadores, sendo 20 doutores. Hoje, tem um quadro fixo de 12 pesquisadores e um faturamento de R\$ 1 milhão.

A Extracta implantou um Banco de Biodiversidade Química de cerca de 30.000 substâncias extraídas da natureza brasileira, de composição química conhecida. Coube à Extracta desenvolver o sistema de testes que permitiu fazer a triagem dos compostos naturais. As novas moléculas de interesses farmacêuticos foram patenteadas pela Extracta e tiveram seu uso licenciado com exclusividade pela Glaxo-Wellcome, a quem caberá o desenvolvimento final do produto, os testes clínicos e a comercialização mundial.

O contrato entre Glaxo-Wellcome e Extracta foi concluído em 2002, após 183 excursões que percorrreram mais de $10.000 \mathrm{~km}^{2}$ de áreas biodiversas, determinando mais de dez compostos bioativos. Em conseqüência do relato prestado pelo presidente da Glaxo-Wellcome do Brasil, foi encaminhado pedido de informações aos Ministérios do Meio Ambiente e da Ciência e Tecnologia, que retornaram resposta informando o desconhecimento de tal acordo. Neste ínterim, foi requerida à Comissão da Amazônia e de Desenvolvimento Regional (CADR) da Câmara dos Deputados a realização de audiência pública para debater os convênios celebrados entre indústrias farmacêuticas e instituições públicas de ensino e pesquisa na área de biotecnologia. Após a apreciação do contrato, este foi aprovado por não ter sido considerado lesivo ao patrimônio social, ao meio ambiente 
e aos interesses do povo brasileiro. A Extracta explorou a biodiversidade brasileira sem entraves até 2000 , pois, até então, o Brasil não dispunha de nenhuma lei que regulamentasse a atividade.

De forma análoga, os primeiros contratos de bioprospecção realizados no Peru foram concebidos no vácuo de uma legislação nacional sobre o tema. Esta trajetória começa em 1993, quando é firmada uma parceria envolvendo um consórcio norte-americano de organizações públicas e privadas, duas universidades peruanas e uma organização de representação dos interesses das comunidades indígenas Aguaruna.

O percurso controvertido deste acordo exerceu influência significativa no processo de institucionalização da regulação da exploração dos recursos da biodiversidade no país. O contrato foi selado quando não apenas o Peru, mas todos os países signatários da Convenção ainda não dispunham de regimes nacionais de regulação do acesso a recursos genéticos e conhecimento tradicional. $\mathrm{Na}$ ausência de uma legislação nacional, os termos do acordo foram negociados diretamente entre os parceiros, sem a mediação do Estado peruano (GREENE, 2004; HAYDEN, 2003).

O contrato foi concebido no âmbito do programa International Cooperative Biodiversity Group (ICBG), criado em 1991 e financiado com recursos de agências norteamericanas, como o United States Agency for International Development (USAID) e o National Institutes of Health (NIH). Em 1993, uma equipe da Washington University foi contemplada com uma linha de financiamento. $\mathrm{O}$ contrato original previa a participação da seguinte rede de atores: a Washington University, a Universidade Peruana Cayetano Heredia (UPCH), o Museu de História Natural da Universidade San Marcos e os Aguaruna, um grupo indígena que habita a região amazônica peruana, representado por uma organização, o Conselho Aguaruna-Huambisa. Neste arranjo, os quatro participariam da coleta de material biológico; a pesquisa para isolamento de princípios ativos seria realizada pela Washington University e pela Universidad Peruana Cayetano Heredia, e à Universidade San Marcos caberia a tarefa de catalogar um inventário da biodiversidade peruana.

Em 1994, o Conselho Aguaruna-Huambisa e a equipe do ICBG assinaram um contrato onde a Washington University comprometia-se a realizar um pagamento anual pelo trabalho de coleta de material e pelas amostras de plantas obtidas. Logo após, a equipe da Washington University retorna aos EUA para formalizar a participação de uma empresa privada no arranjo. Esta deu-se sob a forma de um contrato de licenciamento entre a universidade e a G.D. Searle \& Co., então braço farmacêutico da Monsanto Corporation. Pelos termos do contrato, a Washington University tornou-se a representante legal e única intermediária entre os parceiros peruanos e a Searle.

O que ocorreu a seguir foi a contestação do arranjo entre o Conselho Aguaruna-Huambisa e a Washington University. Durante este período, a equipe de pesquisadores da Washington University retorna ao Peru para a coleta de amostras nas proximidades de uma reserva não-indígena, chamada Imazita, fato que provocou fortes atritos entre a a equipe do ICBG e o Conselho Aguaruna-Huambisa. No início de 1995, o Conselho Aguaruna-Huambisa retirou-se do projeto e o ICBG retornou ao Peru para consolidar os termos do acordo com outra organização indígena, a Organização Central de Comunidades Aguarunas do Alto Maranhão (OCCAAM). Ao tomar conhecimento, o Conselho Aguaruna-Huambisa enviou uma carta de protesto à Washington University e ao National Institutes of Health. Entre outras reivindicações, a carta alegava que a Washington University tinha negado ao Conselho informação suficiente sobre o contrato de licença com a Searle e que a primeira havia retirado amostras de território Aguaruna sem a devida autorização.

A evolução do caso resume-se na trajetória da equipe do ICBG e da OCCAAM para ampliar sua legitimidade através da conquista de aliados. Assim, ocorreu a associação da OCCAAM com outras três organizações indígenas: Federação Aguaruna Domingusa (FAD), Federação de Comunidades Nativas Aguarunas do Rio Nieva (FECONARIN) e Organização Aguaruna Alto Mayo (OAAM). O "mote" desta aproximação foi a inclusão dessas organizações no projeto ICBG e no arranjo de repartição de benefícios. O passo seguinte foi a escolha da Confederação de Nacionalidades Amazônicas do Peru (CONAP), uma das maiores federações indígenas do Peru, para representar este consórcio de organizações junto à Searle.

O trabalho de campo recomeçou em 1996. Os testes limitaram-se à tentativa de identificação de princípios ativos para tratamento de diabetes e problemas cardiovasculares, abordagem que prescindiu da maioria das informações colhidas junto às comunidades Aguaruna. Em setembro de 1999, a Searle cancela o contrato com a equipe do ICBG sob a alegação de que os testes não haviam indicado uma linha de pesquisa atraente em termos de custo-benefício.

Além deste projeto, outras experiências influenciaram significativamente o processo de construção do quadro normativo para regulação da bioprospeção no Peru. Um dos casos mais representativos foi o processo de contestação da patente do extrato da planta Maca, planta cultivada há muitas gerações pelas populações andinas. Desde a década de 1990, no rastro dos lucros alcançados pela Pfizer com a comercialização do Viagra, a planta tem atraído a atenção de empresas do ramo farmacêutico e fitoterápico, sendo freqüentemente divulgada nos meios de comunicação sob o rótulo de "viagra natural".

Em julho de 2001, uma norte-americana, a Pure World Botanicals, após a identificação e isolamento dos princípios ativos da raiz da planta, entrou com pedido de registro do extrato junto ao Escritório de Patentes Norte-Americano, que foi concedido. A contestação da patente foi feita em julho de 2002, na sede do Fórum Ecológico de Lima, e reuniu: organizações de base (federações indígenas e lideranças rurais), organizações não-governamentais nacionais (Sociedade Peruana de Direito Ambiental - SPDA) e internacionais (ETC 
Group) e o governo peruano, através do Instituto Nacional de Defesa da Competência e da Proteção da Propriedade Intelectual (INDECOPI). A coalizão exigiu do governo peruano que fosse investigado o registro de todas as patentes de produtos e/ou processos derivados da utilização do conhecimeno tradicional e dos recursos da biodiversidade peruana.

A empresa americana reagiu às denúncias de biopirataria, declarando que seus procedimentos satisfaziam os critérios da legislação norte-americana de patentes. A coalizão peruana contra-argumentou com base no princípio da existência de um conhecimento prévio acerca dos efeitos terapêuticos da planta, sem o qual o screening não poderia ter sido realizado.

A assimetria entre as partes litigantes e os altos custos envolvidos em um processo internacional de contestação de patentes obstacularizaram a tentativa de impugnação da patente norte-americana. Isto não significa que outras estratégias não tenham sido organizadas pelos atores peruanos. $\mathrm{O}$ conflito gerou um movimento de reação que resultou na criação de um grupo de trabalho multissetorial para rastrear os registros de patentes relacionadas com a exploração de recursos da biodiversidade e conhecimento tradicional, que institucionalizou-se sob o nome de Comissão Nacional para a Proteção da Biodiversidade, em 2004. Entre os principais projetos da Comissão estão a alimentação de um banco de dados digital para rastreamento dos recursos da biodiversidade e a criação de um certificado internacional de identificação de origem.

Finalmente, do exame preliminar da trajetória de acordos de bioprospecção no Brasil e no Peru, observa-se os seguintes aspectos:

- Um descompasso entre as expectativas iniciais e os resultados efetivos dos projetos, seja em termos do desenvolvimento de novos produtos ou processos, da promoção das capacidades científicas e/ou tecnológicas dos países do sul ou da repartição de benefícios com as comunidades autóctones.

- O caráter essencialmente reativo e não-estabilizado do processo de construção do quadro normativoinstitucional, nos dois países.

- A centralidade exercida pela questão da propriedade intelectual. Não obstante a complexidade do tema, aponta-se como tendência futura a ampliação dos mecanismos do tipo "rights first, access later" (TOBIN, 2005), a exemplo de regimes de certificação de origem, como os instrumentos mais prováveis para a regulação do acesso aos recursos genéticos provenientes de reservas de biodiversidade.

- A existência de visões conflitantes em torno do papel das organizações não-governamentais, quanto aos limites para essa atuação e quanto à legitimidade de que se revestem como porta-vozes de vários outros segmentos sociais na prática bioprospectiva, como os grupos indígenas. A literatura divide-se entre uma visão da atuação dessas organizações como parte de um projeto neo-liberal para disseminação de um conceito equivocado de emancipação de populações marginalizadas, enquanto outros enxergam nas mesmas um vetor de assistência às comunidades excluídas (GREENE, 2004).

Quanto às visões de futuro da prática bioprospectiva, a percepção parece estar dividida entre uma visão mais otimista e outra mais cética entre os especialistas. $\mathrm{O}$ debate sobre a busca de modelos normativos revela uma realidade de difícil estabilização e uma condição de relativa ambigüidade quanto a que estratégias desenvolver (TRIGUEIRO, 2006). Restam, portanto, dúvidas as mais diversas. Talvez esse seja o principal atrativo da investigação do tema da bioprospecção: a possibilidade de levantar questões que apontem para aspectos ainda não explorados, ou que sugiram a necessidade de dedicarmos maior atenção à análise da complexidade do fenômeno.

\section{Referências bibliográficas}

BRUSH, S. B. Bioprospecting the public domain. Cultural Anthropology, v. 14, n.4, p.535-555, 1999

CARNEIRO DA CUNHA, M. Populações tradicionais e a convenção da diversidade biológica. Estudos Avançados, v.13, n.36, p.24-39, 1999.

COOMBE, R. The recognition of indigenous peoples' and community knowledge in international law. St. Thomas Law Review, v. 14, n.2, p.275-285, 2005.

DUTFIELD, G. Repartindo benefícios da biodiversidade - qual o papel do sistema de patentes? In: VARELLA, M. D.; PLATIAU, A.F.B. (Org.), Diversidade biológica e conhecimentos tradicionais, Coleção Direito Ambiental, v.2, 2004, p.57-107.

GREENE, S. Indigenous people incorporated? culture as politics, culture as property in pharmaceutical bioprospecting. Current Anthropology, v.45, n.2, p.32-5 1, apr. 2004.

HAYDEN, C. When nature goes public - the making and unmaking of bioprospecting in Mexico, 1.ed., Princeton: Princeton University Press, 2003, 274p.

LATOUR, B. Ciência em ação: como seguir cientistas e engenheiros sociedade afora. 1 ed., SP, 2000, 438p.

LATOUR, B. Políticas da natureza: como fazer ciência na democracia. São Paulo: Edusc, 2004, 41 lp.

LE PRESTRE, P. Ecopolítica internacional, 1. São Paulo: Senac, 2000, 518p.

SANTILI, J. Conhecimentos tradicionais associados à biodiversidade: elementos para a construção de um regime jurídico sui generis de proteção, In: Encontro da Associação Nacional de Pós-graduação e Pesquisa em Meio Ambiente - ANPPAS, 2., 2004, Indaiatuba, Anais... Indaituba: ANPPAS, 2004, p.1-15.

SOUSA SANTOS, B.; MENEZES, M.P.; NUNES, J. A. Para ampliar o cânone da ciência: a diversidade epistemológica do mundo, In: SOUSA SANTOS, B. (Org.) Semear outras soluções: os caminhos da biodiversidade e dos conhecimentos rivais. Porto: Afrontamento, 2004, p. 18-56. 
SHIVA, V. Biodiversidade, direitos de propriedade intelectual e globalização, In: SOUSA SANTOS, B. (Org.) Semear outras soluções: os caminhos da biodiversidade e dos conhecimentos rivais. Porto: Afrontamento, 2004, p.18-56.

TOBIN, B. Biodiplomacy: bringing "life" to interna- tional negotiations. UNU-IAS Working Paper, Tokyo, v. 17, n.2, 2005. Disponível em: http://www.ias.unu.edu. Acesso em: março 2006.

TRIGUEIRO, M.G.S. Bioprospecção: uma nova fronteira da sociedade, Campinas: IG-UNICAMP, 2006, $116 \mathrm{p}$, mimeo.

\section{Sobre as autoras}

\section{Camila Carneiro Dias}

Doutoranda do Departamento de Política Científica e Tecnológica do Instituto de Geociências da Universidade Estadual de Campinas (DPCT/IG/UNICAMP) desde 2005, onde desenvolve o projeto "Natureza e Impacto da Produção e Utilização de Conhecimento em Biotecnologia Aplicada à Bioprospecção: o Caso do Peru", sob a orientação da Profa. Maria Conceição da Costa. É Mestre em Administração pelo Núcleo de Pós-Graduação em Administração da Universidade Federal da Bahia (NPGA-UFBA), onde desenvolveu a dissertação "Conflito, Cooperação e Aprendizado nos Complexos Agroindustriais: o Caso do Instituto Biofábrica da Cacau de Ilhéus, Bahia" sob a orientação da Profa. Elizabeth Loiola. Foi professora substituta da Escola de Administração da Universidade Federal da Bahia (2000-2003) e consultora da Federação das Indústrias do Estado da Bahia (2002-2004). Seus interesses de pesquisa incluem: Estudos Sociais da Ciência e da Tecnologia; Meio-Ambiente; Agroindústria.

\section{Maria Conceicão da Costa}

Possui graduação em Ciências Sociais pela Universidade Estadual de Campinas (1983), mestrado em Ciência Política pela Universidade Estadual de Campinas (1991), doutorado em Ciência Política pela Universidade de São Paulo (1997) e pelo Institut d'Etudes Politiques, Grenoble (1992-1993), e pós-doutorado em Sociologia da Ciência pela University of South Florida, Tampa, nos Estados Unidos (2001-2002). Atualmente é professora doutora da Universidade Estadual de Campinas (UNICAMP). Possui experiência na área de Sociologia da Ciência e Ciência Política, com ênfase em Estudos Sociais da Ciência, atuando principalmente com os seguintes temas: dinâmica do conhecimento científico, cooperação internacional e gênero e ciência. 